\title{
Recent Issues in Studies of Magnetosphere-Ionosphere Coupling*
}

\author{
Y. KAMIDE \\ Kyoto Sangyo University, Kyoto 603, Japan
}

(Received October 2, 1987; Revised November 9, 1987)

\begin{abstract}
This paper attempts to highlight progress in studies of magnetosphereionosphere coupling made during the last two years using a wide variety of techniques, covering a broad range of topics. Emphasis is placed on pointing out the key issues in the area that need substantial innovation in the near future. This includes the problem of differentiating between the substorm expansion and enhanced convection, and the importance of time-dependent treatment of the entire magnetosphere-ionosphere coupling system.
\end{abstract}

\section{Introduction}

VASYLIUNAS (1970) was one of the first to stress that the magnetosphere and the ionosphere must be examined as an entire system. There are several different improved versions of Vasyliunas's original diagram, including for practical purposes of calculation; see Fig. 1. The purpose of this review is to highlight some of the studies carried out over the 1985-1987 period in the field of magnetosphere-ionosphere coupling, and to discuss the main issues of magnetosphere-ionosphere coupling studies by choosing several topics from physical processes occurring in the system in Fig. 1. We admit that it is not possible to provide here a complete and unbiased review, partly because of the page limit.

During the last two years there have been 200-300 publications in this area, depending upon how we define magnetosphere-ionosphere coupling. There have also been published several review papers summarizing and evaluating the recent progress in studies of magnetosphere-ionosphere coupling. These include the works by FÄlThAMMAR (1986), MAUK and ZANETTI (1987), GORNEY (1987), HEELIS (1987), and SISCOE (1987). Each one of these articles has its own point of emphasis. For example, Fälthammar tried to view magnetosphere-ionosphere interactions as nearearth manifestations of the plasma universe.

This paper is organized in the following way: First, we shall go through the highlights of the studies in magnetosphere-ionosphere coupling by listing some of the topics that represent the major progress made during the last two years. Then, we shall stress the importance of the "real" coupling, not "one-way" coupling, of electro-

*This paper is based on a reporter review presented at the XIX IUGG/IAGA General Assembly held at the University of British Columbia, Vancouver, in August, 1987. 


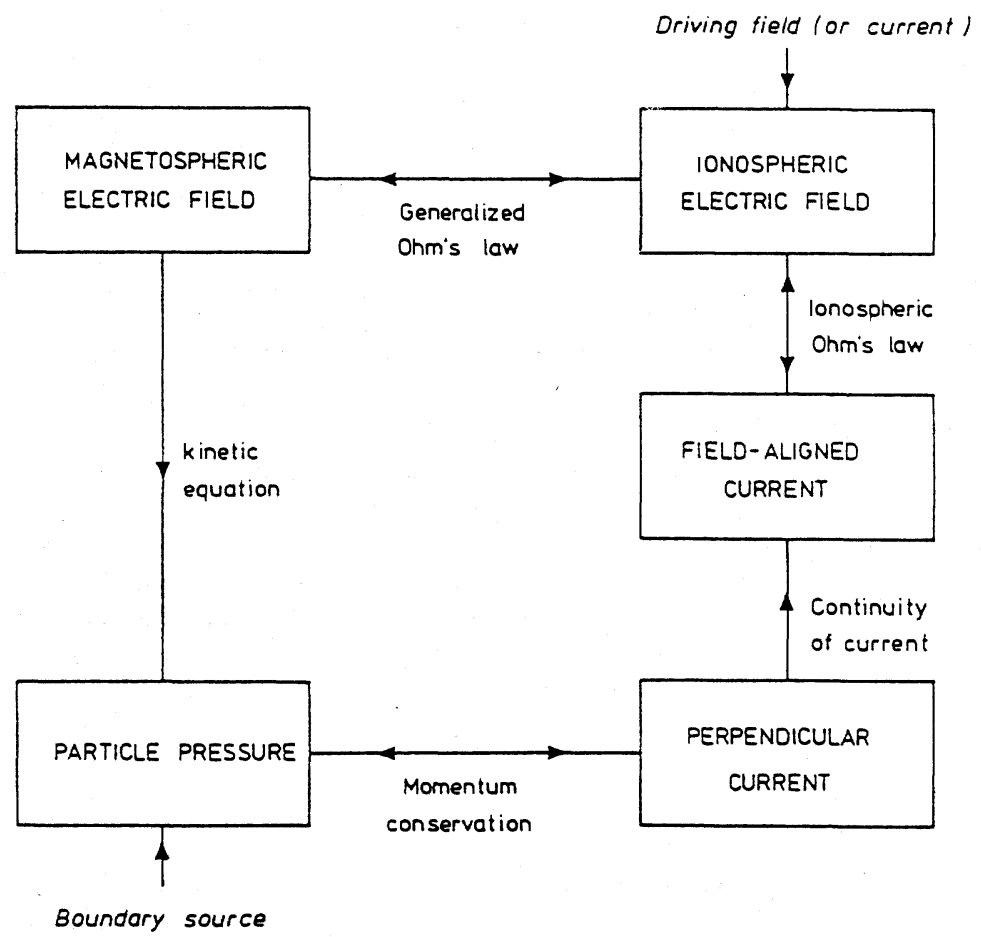

(a)

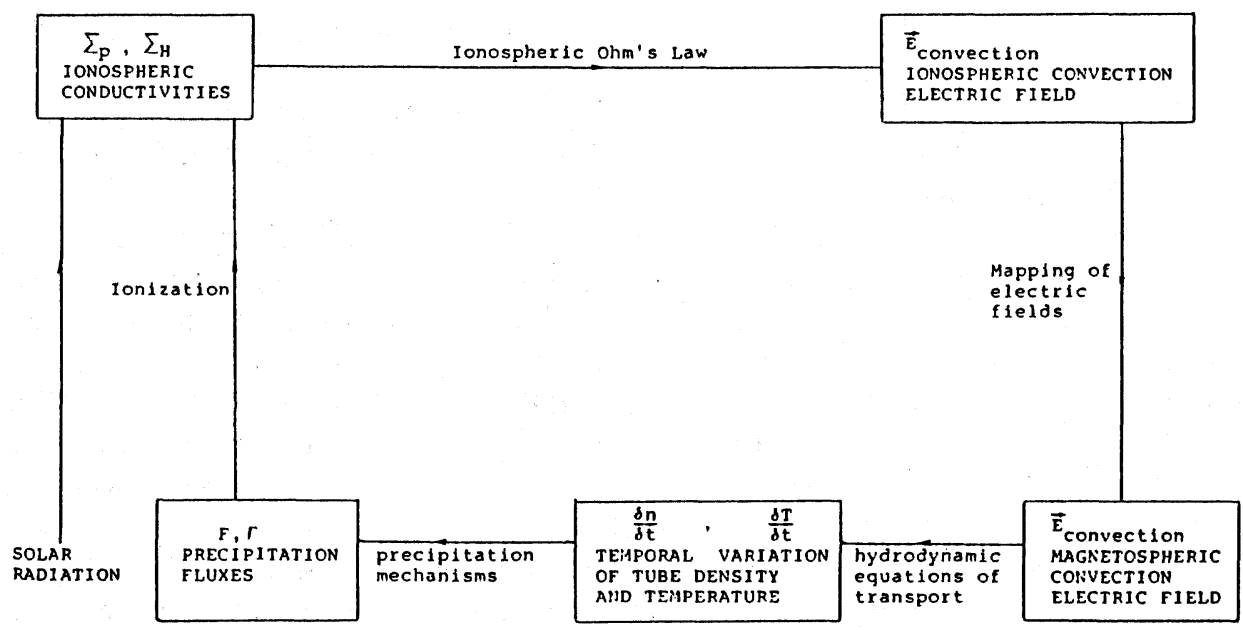

(b)

Fig. 1. (a) Logic diagram for a self-consistent calculation of magnetospheric convection. The boxes indicate quantities to be calculated. Each line joining two boxes is labeled with the physical principle or equation that links the two physical quantities. (After VASYLIUNAS, 1970). Note that although the driving field is connected only to the ionospheric electric field in the original diagram by Vasyliunas, it should also connect to the magnetospheric electric field. (b) Logic diagram of the FONTAINE et al. (1985) calculation, summarizing the physical parameters to be calculated and the physical mechanisms governing them. 
dynamic parameters and of time dependence in modeling or theoretical consideration in this field.

\section{What Makes Our Field So Difficult?}

Our ultimate goal is to understand the whole magnetosphere-ionosphere coupled system self-consistently, not to understand each link in Fig. 1 individually. In other words, as indicated in the previous reporter review (KAMIDE and RICHMOND, 1986), our final goal is to build a computer code that can predict what will be happening in the magnetosphere and the ionosphere. The essence of that computer code in this sense is that it does not contain any empirical parameters. That is, just input the present condition in the solar wind, then the output will tell us how magnetospheric and ionospheric convection increases and decreases, and when and what magnitude of substorm expansion onsets will take place, even how and where the substorms develop. For these predictions to become possible, we must assume that the computer size should have no limit. Most importantly, however, before we start to write practically such a computer code, we must either know the physics or the equations governing the "solar wind-magnetosphere-ionosphere" system, or we must, at least, have the empirical relationships among a number of physical parameters crucial to the system. In one view, our way of approaching the goal is that we are conducting a kind of trial-and-error method between observations aimed at "discovery" and theories aimed at understanding the physics controlling the magnetosphereionosphere system. Our progress may be slow, because observations, which are bounded by a number of limitations, such as those of instrument, orbit, data sampling, etc., give us only a partial hint of the whole picture, and because theories and simulation or modeling studies are based on many unrealistic assumptions that must be tested against the observations. We thus need to proceed by an interplay between ideas and observations.

In our field of magnetospheric and ionospheric physics, we are, thus, far from the dream of predicting everything only from the solar wind condition. We do have a number of simulation models, of both large scale and small scale, which include relatively complicated treatments of the magnetosphere-ionosphere coupling system and which are able to reproduce many of the observed characteristics, but the agreement between the models and the observations is still of a "first approximation" or "averaged" nature. For instance, we do not yet properly understand how the electric field pattern at high latitudes for individual substorms differs uniquely from that of average disturbances.

What makes our field so difficult? The key to this question lies in the "coupling" nature of our near-earth electrodynamic environment. It would in fact be relatively easy to think of a one-way chain of energy flow from the solar wind to the ionosphere. The solar wind energy penetrates into the magnetotail and ends up in the polar ionosphere as auroral displays and electrical currents, as well as heating the upper atmosphere. Research during the last several years, however, has clearly demonstrated the basic role of the so-called feedback or coupled loops instead of the one-way 
chain. More practically, the solar wind cannot control the detailed distribution of where the auroral electrojets should flow or where the Joule heat must be maximized or minimized. The solar wind alone cannot determine the location of auroral breakups. Instead, it only tells us the general level of activity. According to, for example, ATKINSON (1984), it is the ionosphere, not the magnetosphere, that plays a crucial role in setting up the substorm instability.

\section{Highlights of Magnetosphere-Ionosphere Coupling Studies}

\subsection{Electric fields and particle precipitation}

In this section, some of the important studies carried out over the last two years that have led to a better understanding of magnetosphere-ionosphere coupling are listed. There are a number of studies that have been helpful in improving our knowledge of the space/time distribution of ionospheric and magnetospheric parameters, in other words, characteristics of one or two of the "boxes" in Fig. 1. Because of the space limit in this paper, all these results cannot be highlighted. Instead, two such examples of the distribution of ionospheric electric field and of particle precipitation are given. During the last years, our understanding of the high-latitude electric field pattern has been significantly upgraded. Empirical convection models for different IMF (interplanetary magnetic field) orientations have also been developed by using different satellite and radar techniques. These include the works by ALCAYDE et al. (1986), HOLT et al. (1987), and HEPPNER and MAYNARD (1987). By refining the empirical models in this fashion, one will be able to isolate the important parameters that control the convection patterns as well as its intensity. It should be noted here that they all have shown that the convection pattern is highly variable, responding to the substorm phases and changes in the IMF. It may not be incorrect to rephrase this by saying that changes are due to changes in the ionospheric conductivity or the degree or the efficiency of the magnetosphereionosphere coupling, from perfect coupling to null coupling, as well as changes in the magnetospheric structure associated with the plasma sheet motion. The effect of substorms is particularly striking, causing local deformations in the overall pattern and increases in the flow velocities. It is thus important to realize that the empirical models cannot be viewed as providing an instantaneous picture of the pattern.

The model configuration of the electrostatic potential derived by HEPPNER and MAYNARD (1987) on the basis of DE (Dynamics Explorer) data provides the key ingredient for discussing convection patterns for strong northward IMF conditions. For example, some of the positive IMF patterns can be successively explained by merely distorting the so-called two-cell pattern, without adding new convection characteristics, such as additional convection cells: see Subsection 3.5. Figure 2 shows examples of the empirical models of the electric potential distribution under northward IMF conditions. Different from HEPPNER (1977), these configurations have been derived from a number of DE data covering various local times, not only from the dawn-dusk meridian.

A statistical study of auroral electron precipitation has been conducted by 


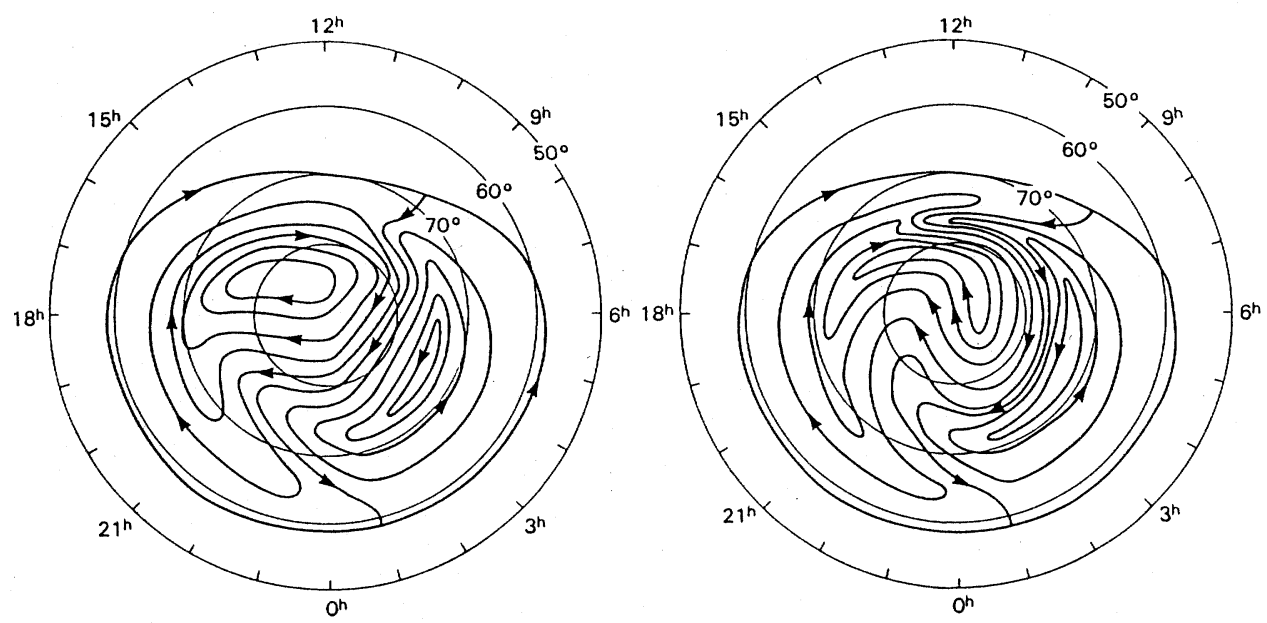

Fig. 2. Empirical models of the electrostatic potential for weakly (left) and strongly (right) positive $B_{z}$ values of the interplanetary magnetic field. (After HEPPNER and MAYNARD, 1987).

HARDY et al. (1985) using DMSP data to determine the average characteristics of electron precipitation as functions of MLT (magnetic local time), latitude, and geomagnetic activity. Plots for average energy, energy flux and number flux all form an auroral belt, but there are also some spatial disagreements among these distributions, such as in the latitudinal width of the enhanced regions and in peak local times. These discrepancies are in fact important in understanding the physics of the magnetosphere-ionosphere system, because they are giving us some hint of how imperfectly the magnetosphere and the ionosphere interact: see also Subsection 3.4 about imperfect coupling between the magnetosphere and the ionosphere. Once again, however, one must be cautious in interpreting these statistical/empirical models in terms of the dynamics of individual substorms. In the following sections, we shall discuss several physical topics that spread over several "boxes," not just one or two, in the loop shown in Fig. 1.

\subsection{Global simulation models}

Computer models for magnetospheric convection, such as the Rice convection model (RCM) and the French model, have been improved in terms of both their numerical methods and their ability to include new physical features. Figure 3 shows a logic diagram for an updated version of the RCM. The main calculations are done on the lines connecting the boxes in the central pentagon. Boxes with rounded corners are input models, which feed information to the central calculations. New physical features included in the version that is currently running are:

a. Equatorial electrojet: Instead of assuming zero current across the equatorward boundary of the scheme, this equatorial electrojet specifies the equatorward 


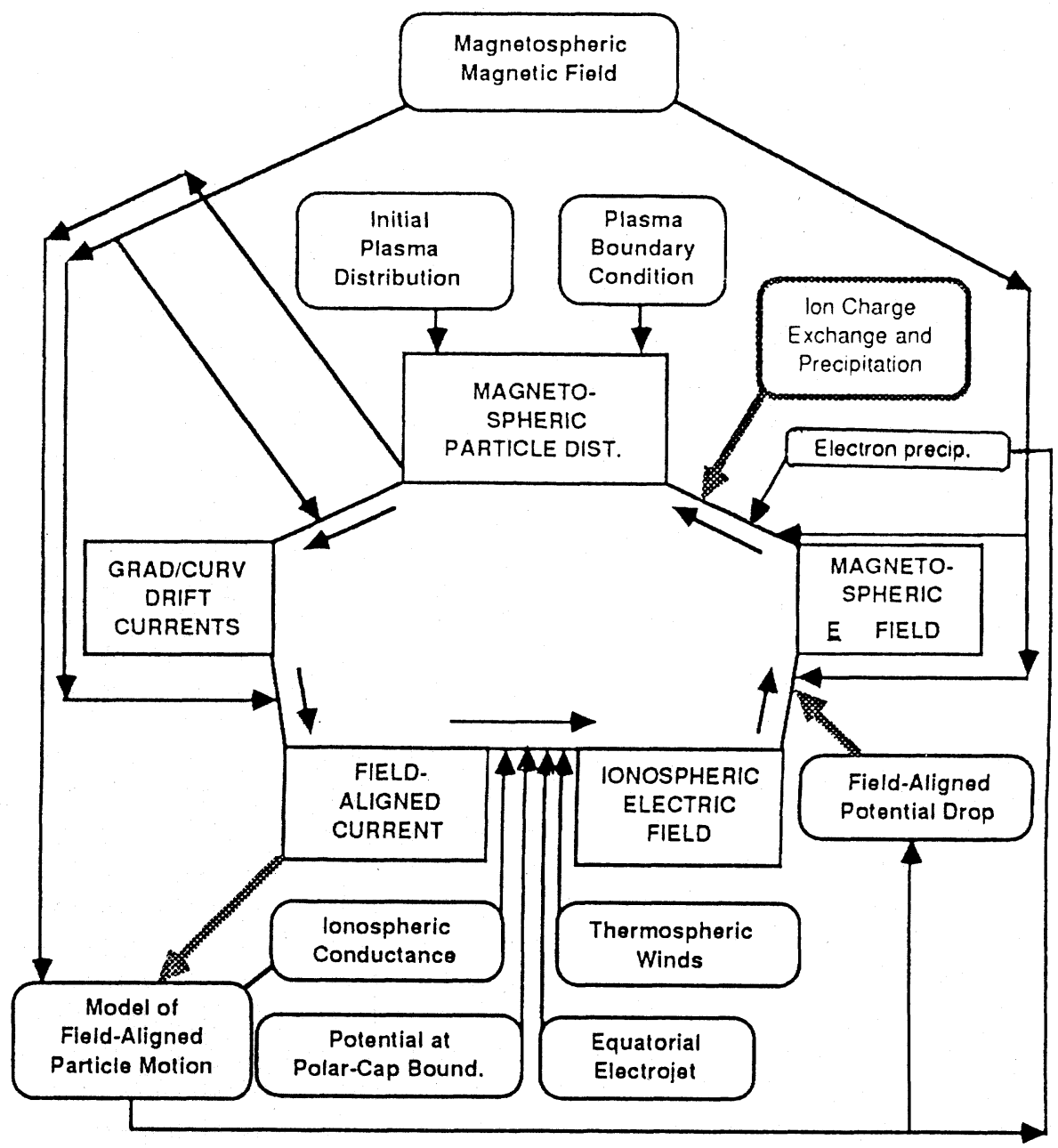

Fig. 3. Logic diagram of the present version of the Rice convection model. The main calculations are to be conducted on lines connecting the boxes in the central pentagon. Boxes with rounded corners are input models, which feed information to the central calculations. Light lines indicate features that are being programmed for future use. (After WoLF et al., 1986).

boundary condition.

b. Thermospheric wind: Winds driven by solar heating and by strong convection change the overall potential pattern obtained only from $\boldsymbol{E} \times \boldsymbol{B}$ drifts.

c. Self-consistent conductance: It is now possible to calculate electron energy flux from the computed plasma sheet. Thus, the auroral enhanced conductance is now computed, rather than taken from empirical statistical conductance models. It is also 
expected that, by the time of the next IAGA assembly, some results will be reported about the effects of more new features, such as the effects of field-aligned potential drop and loss of plasma-sheet ions.

In the French model (e.g., SENIOR and BLANC, 1984), the essence is to view the convection electric field in terms of the dynamic behavior of the ion and electron population through the conductive ionosphere. Both the RCM and the French model employ essentially the same magnetospheric convection approach, but they differ in one major aspect. That is, the French model assumes a simple representation of plasma sheet particles having a monoenergetic plasma distribution with a sharp earthward edge. Recently, FONTAINE et al. (1985) have improved their scheme in two ways: First, the electric field distribution that drives the electron transport in the magnetosphere is now computed from the equation of current continuity, instead of being just described by an empirical model. Second, ionospheric conductivities are given by the precipitating electron flux. The magnetic flux tubes which are populated by the electrons injected from the magnetotail are driven earthward under the influence of the convection electric field. During this "transport" process, electron precipitation occurs whenever the pitch angles of these electrons reach the loss cone. The precipitation causes ionization in the upper atmosphere, generating enhancements in the ionospheric conductances, which in turn induces changes in the electric field at auroral latitudes. These changes are to be communicated along field lines into the magnetosphere, where the plasma sheet electron transport must be modified.

New developments from two of the most recent works have become available on time-dependent, quantitative modeling of the magnetosphere-ionosphere coupling system. The first laborious work of three-dimensional modeling of the magnetosphereionosphere coupling has been conducted by WATANABE et al. (1986), solving fluid MHD equations. In their scheme, a simple model of the electric field is initially given on the magnetospheric equatorial plane. After some time in their computer simulation, the ionosphere responds to the given electric field and reaches some kind of steady state, if the original field is kept unchanged. It is conceivable that the electrostatic potential in the ionosphere depends on the ionospheric plasma density. The resultant potential contours and field-aligned current distribution at the "final" state are found to be similar to the observed patterns. Although it is as yet preliminary, in the sense that they solved MHD equations for zero parallel potential and constant ionospheric conductivity, the result still confirmed many observed features, including that the twin-vortice potential pattern can develop slowly or rapidly, depending on the ionospheric conductivity.

The second one is by $\mathrm{ZI}_{\mathrm{I}}$ and SHEN (1986), who have studied the effect of the day-night gradients in the ionospheric conductivity on the magnet osphere-ionosphere coupling. For this purpose, a time-dependent analytical model on the basis of the Senior-Blanc convection model has been developed. Figure 4 shows a self-consistent coupling chain, in which analytical solutions are deduced for a simple driving potential $\Phi$, which is applied to the magnetosphere initially and remains invariant later on. Figure 5 shows a sample of the time evolution of the global potential distribution for a very simple sinusoidal potential. It is found that the time constant of 


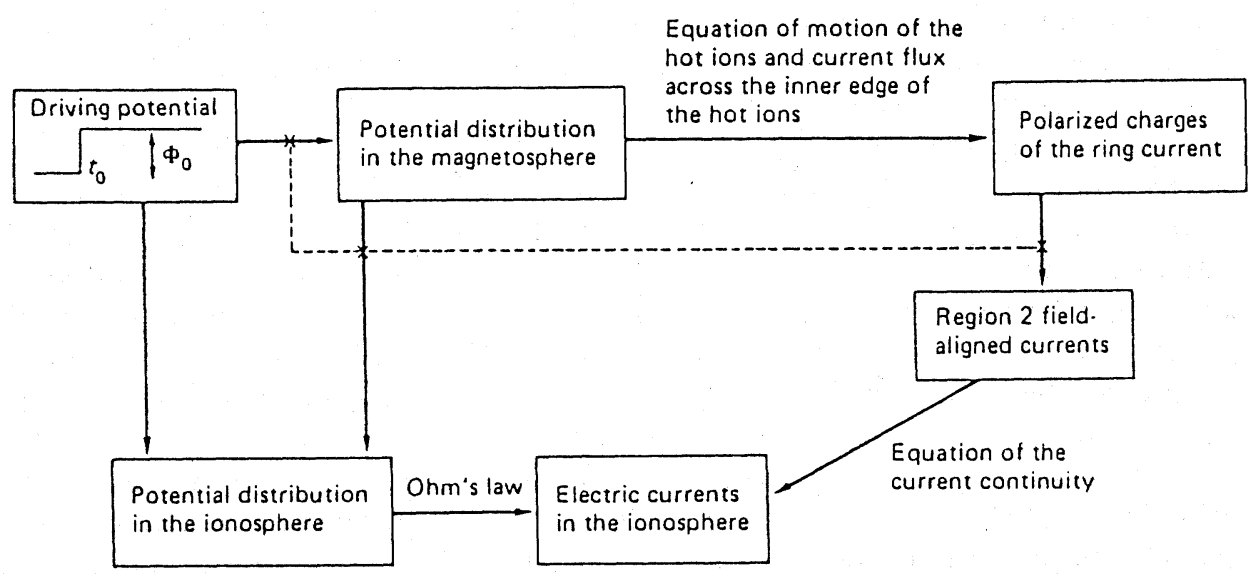

Fig. 4. Schematic diagram of the magnetosphere-ionosphere electric field coupling. The lower part of the diagram (below the dotted line) shows the outline of the study for steady states. The step function of the driving potential is used for the $\mathrm{ZI}$ and SHEN (1986) model.

the evolution toward the steady state varies with local time, when the non-uniform conductivity is introduced. This confirms one of the earlier results of the RCM. The feature predicted by the model calculation for field-aligned currents is also in reasonable agreement with the statistical configuration of recent satellite measurements.

\subsection{Relative location of electric fields and particle precipitation}

FOSTER et al. (1986) have conducted a very interesting study that has a potentially important implication for magnetosphere-ionosphere coupling. In their work, convection electric fields from Millstone Hill observations and NOAA/TIROS particle precipitation are spatially compared for various levels of particle precipitation activity. In the first approximation, there is good agreement between these two, in the sense that both electric field and particle precipitation are enhanced in the auroral belt. After a careful examination, however, it is apparent that there is a shift in the peak latitude of the electric field and particle precipitation, and moreover that the degree of the shift is strongly influenced by local time. Assuming that the electron precipitation influences more or less directly the conductivity enhancement in the ionosphere, this discrepancy indicates the relative importance of the electric field and the conductivity within the auroral electrojets. Figure 6, taken from FOSTER (1987), shows the latitudinal profile of the electric field magnitude (solid curve), the Hall conductance (a dashed curve from FULLER-ROwELL and EVANS, 1987), and their product, which is the Hall current (dotted curve) for the dawn sector. It is noticeable, as KAMIDE and RICHMOND (1987) pointed out, that the electric field magnitude at 0400 MLT peaks at least $5^{\circ}$ poleward of the Hall conductance and is the stronger 

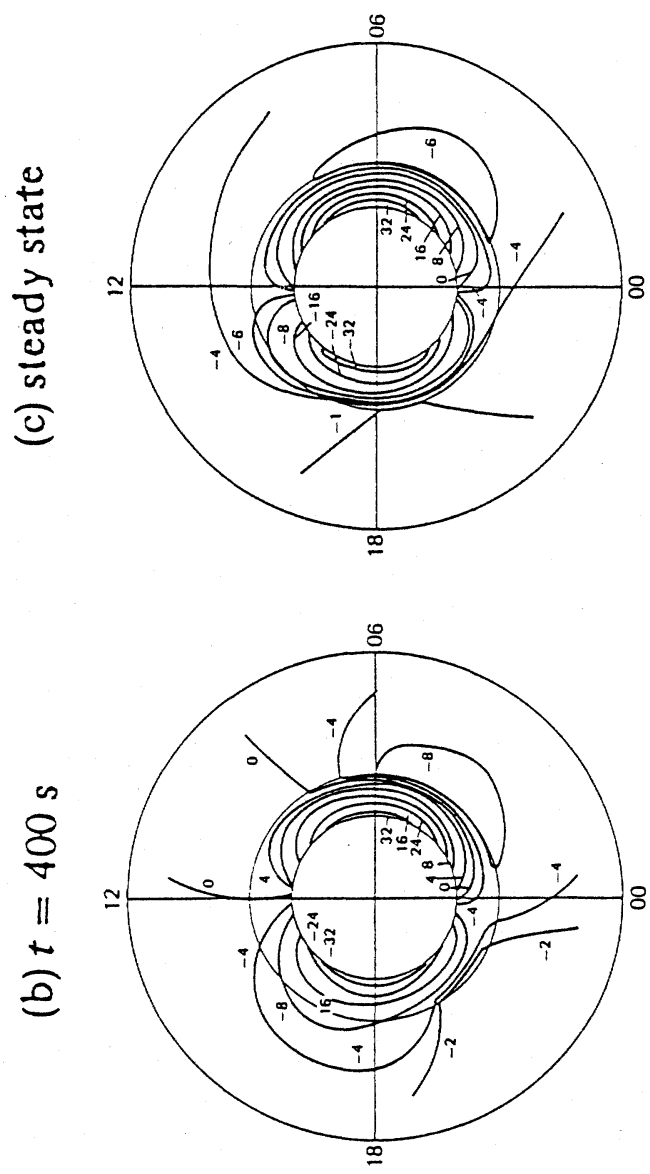

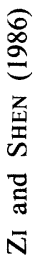

Е

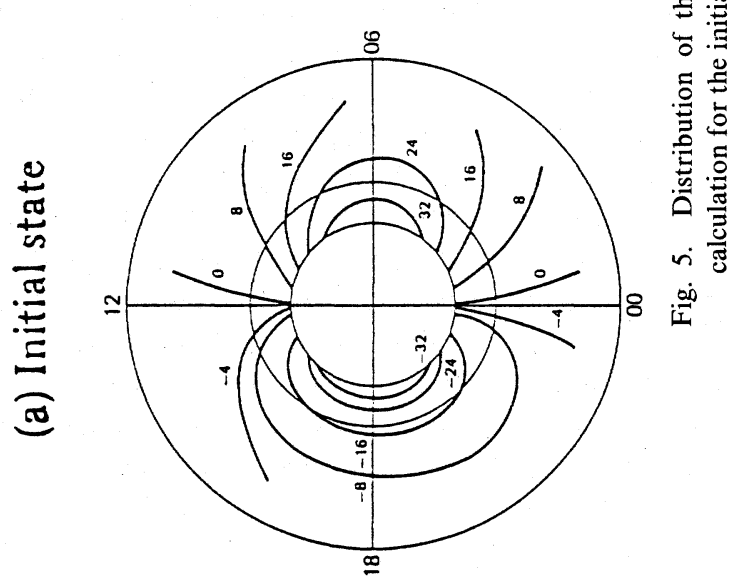




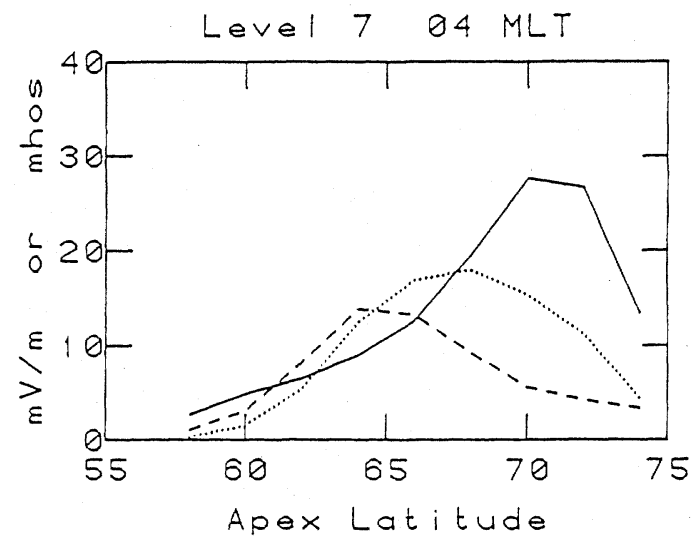

Fig. 6. Latitudinal distribution of the electric field (solid line), the Hall conductivity (dashed line) and the Hall current (dotted line) for 0400 magnetic local time. (After FosTER, 1987).

contributor to the poleward half of the westward electrojet in the morning sector. The physical implication of this is important in that the relative locations of the electric field and particle precipitation provide us with a crucial hint that might help to determine which processes are dominant at which places, although what Fig. 6 indicates is still of statistical features.

\subsection{Westward traveling surge}

The westward traveling surge (WTS) is not merely one of the many different auroral forms associated with polar substorms. In fact, the WTS is the most important region for understanding substorm dynamics, because it is the region where the aurora is brightest and where the auroral breakup starts. The WTS is, in the simplest terms, the westward end of the westward electrojet as it expands westward starting near local midnight at the substorm expansion onset. "Steady-state" models of the WTS were developed several years ago. During the last two years, however, efforts have been made to develop a dynamic model of the WTS. ROTHWELL et al. (1984) have proposed a unified model for propagation of the WTS that can explain the diversity in the observed WTS characteristics. They started with the so-called partial Cowling model where both the Hall and Pedersen currents are included. The essence of the new dynamical model is that precipitating electrons at the conductivity gradient modify that gradient, causing the region of the gradient to propagate as a wave front. The model predicts that the motion of the WTS is controlled by three factors: (1) the energy and intensity of precipitating electrons, (2) the Hall-toPedersen conductivity ratio, and (3) the degree of ionospheric current closure into the magnetosphere.

Although geomagnetic pulsations and magnetospheric substorms have often been treated as separate topics, during the last several years, there have been papers 
that try to combine the two phenomena physically, in particular the WTS and pulsation phenomena, which share some common properties including their spatial localization and propagation velocities. KAN and SUN (1985) and SUN and KAN (1985) treated the WTS and Pi 2 pulsations as a consequence of an enhanced magnetospheric convection. The important ingredient of this model is the bunching of Alfvén waves launched by the suddenly enhanced convection. They treated reflection of Alfvén waves from the ionosphere where the conductivity is assumed to be nonuniform. The results of the simulation, including the convection pattern, the electrojets, the field-aligned current, the conductivity enhancement, the oscillation of the westward electrojet and the average speed of the westward surge, are in reasonable agreement with the features of the WTS and the Pi 2 pulsations during substorms. ROTHWELL et al. (1986) related the poleward development of the WTS and Pi 2 pulsations. On the basis of the so-called feed-back instability theory (see SATO, 1982), it has been shown that the velocity of the poleward surge increases when the energy of precipitating electrons is enhanced, in turn, when higher Pi 2 frequency components are generated.

\subsection{Effects of northward IMF}

The "quiet" state of the magnetosphere, during times of northward IMF, continues to attract much attention. What was found from these recent studies was that the quiet state was not really quiet. Quiet was only at auroral latitudes, not in the polar cap! During the last two years, a number of reports provided evidence that, as the IMF becomes strongly northward, a great variety of fascinating phenomena tend to take place in the region beyond the auroral belt. The state of the magnetosphereionosphere system for the northward IMF has been investigated during the past several years primarily in the following four respects:

1. Auroras, by the DE and Viking spacecraft.

2. Convection electric fields observed by polar-orbiting satellites and groundbased radars and estimated from ground-based magnetometer data.

3. NBZ field-aligned currents observed by polar-orbiting satellites.

4. Particle precipitation studied by polar-orbiting satellites.

5. Neutral winds observed by DE.

6. Computer simulations of ionospheric electric fields and currents.

FRANK et al. (1986) have given a summary of theta auroras, which are one of the dominant features of the northward IMF and march in the dawn-to-dusk direction with changes in the IMF $B_{y}$ components. It has been shown by using simultaneous DE 1 and DE 2 data that the plasma convection in the region of the theta auroras is sunward, and elsewhere over the polar cap it is antisunward. Field-aligned acceleration into the polar atmosphere and field-aligned current are present in the theta auroras. The origin of the plasma in the aurora has also been discussed. They identified two components of the hot plasma, one from the ionosphere below and the other from the distant tail, providing evidence that the cross-polar cap auroras occur on field lines closing through the distant plasma sheet or plasma sheet boundary layer. These observations should provide a foundation for future theoretical efforts. 
Theoretical models of the generation of the theta aurora have been discussed in several papers, including LYONS (1985), CORNWALL (1985), and KAN and BURKE (1985). RASMUSSEN and SCHUNK (1987) calculated the effects of an addition of the NBZ current system on ionospheric convection. The appearance of the so-called four-cell convection pattern depends on the relative strength of region 1 and 2 field-aligned currents and the NBZ current.

Neutral winds during periods of strongly northward IMF have been measured by DE 2 (KILLEEN et al., 1985). The multi-cell ion drift pattern associated with positive $B_{z}$ has been observed to drive a similar but weaker neutral wind system, indicating the relatively long time constant (a few hours) for momentum exchange between the ion and neutral gasses. Note that the motion of the neutral air in the polar upperatmosphere is controlled primarily by ion-to-neutral gas momentum transfer (e.g., KILLEEN et al., 1984; ROBLE et al., 1984). Thus, if the northward IMF has a relatively large and steady value, as during the cases of KILLEEN et al. (1985), we should be able to observe a unique neutral wind pattern corresponding to the ion convection characteristic of northward IMF, although small-scale fluctuations in the ion convection driven by the IMF variability may be smoothed out by the neutral air motion. (1985).

This is not inconsistent with the fly-wheel model proposed by LYONS et al.

In modeling electrodynamics for the northward IMF, it is not permissible to discuss each topic of the above six individually: any model must be able to explain all these features consistently. Another point, however, is that when the IMF $\boldsymbol{B}_{\boldsymbol{z}}$ component becomes positive, the other two components, $B_{x}$ and $B_{y}$, become equally, or even more, important than the positive $B_{z}$ component in controlling various upper atmospheric phenomena in the polar cap. Therefore, in constructing convection models for positive $B_{z}$, it is important to distinguish at least two cases, depending on whether $B_{z}$ is much greater or smaller than $B_{y}$.

In spite of the considerable amount of new observations that have become available during the last two years, there are still a number of fundamental issues left unsolved in the study of the convection pattern for northward IMF periods. One drawback of satellite observations in this regard is that the electric field is measured only along the satellite orbit every 100 minutes, so that it is difficult to infer an instantaneous flow pattern over the entire polar region. The radar measurements are limited also in their "field-of-view."

Another question concerns the stability of the northward IMF features, such as the NBZ current system. Early studies using data from polar-orbiting satellites indicated little change in the NBZ current system and in the sun-aligned auroral arcs for periods as long as 10 hours. We note, however, that this persistence may be simply because only intervals when the IMF was strongly northward for that long a time were examined. The question, instead, is: What happens in the polar cap, in convection or currents or auroras, when the IMF is fluctuating? Do we always have the four-cell pattern when the IMF $B_{z}$ becomes positive? The answer is probably No. AHN et al. (1987) have shown that the typical four-cell pattern does not always appear whenever 
the IMF is directed northward. HEPPNER and MAYNARD (1987) have argued that electric field data only from one polar-orbiting satellite cannot really tell us whether the four-cell pattern is there or the normal two-cell pattern is just skewed locally (see Fig. 2). If these suggestions are correct, we may be able to state that the magnetosphere-ionosphere system does not prefer having the four-cell pattern. It appears in the polar cap only when that system cannot hold the two-cell pattern, for example, when the IMF is persistently northward for several hours or more. We do not know why this is. The probabilities of having northward and southward IMF are 50:50, but the probability of observing the four-cell pattern is well below $50 \%$.

\subsection{Penetration of high-latitude electric fields into low latitudes}

Two distinct mechanisms of the penetration of high-latitude electric fields into mid-and low-latitudes have been proposed. The first type of ionospheric, low-latitude response to the high-latitude electric fields that couple to the magnetosphere via field lines is the result of what we call "direct" penetration of the convection electric fields into low latitudes. This is equivalent to the leak or non-shielding of electric fields in the distant plasma sheet toward lower L shells. The penetration of this type can be expected during periods of rapid changes in electric fields in the magnetosphereionosphere system, such as DP 2 and substorms. The second type of the low-latitude response is through the action of the ionospheric dynamo which results from global thermospheric wind circulation associated with energy input, e.g., Joule heating of the auroral electrojets.

In the last decade it has become possible to make direct measurements of electric fields and currents in the ionosphere by means of incoherent scatter radars. It was hoped that this would enable us to assess the relative importance of the two mechanisms quantitatively, but as was pointed out by TANAKA (1986) and SPIRO et al. (1987), the separation of the electric field effects due to "direct" penetration from those caused by thermospheric wind effects is quite difficult without having measurements at, at least, several different latitudes.

Outstanding advances include the enormous volumes of data obtained from the incoherent scatter radars and an extensive, semi-analytical treatment of magnetospheric convection by SENIOR and BLANC (1984). Their calculations show that the enhancement of the auroral conductivities by electron precipitation significantly increases both the characteristic duration time and the degree of the penetration of the convection electric fields to mid-latitudes. A good agreement is found in general between the experimental latitudinal profile and the model prediction. By combining ground-based magnetic records with coherent and incoherent scatter radar data and comparing these data to the predictions of the Senior and Blanc convection model, MAZAUDIER et al. (1987) interpreted the deviations of the observed electric fields from the model predictions as resulting from (1) the transient responses of the ionosphere to IMF time variations, (2) the effects of individual substorms, and (3) neutral wind disturbances.

An excellent review article by FEJER (1986) has also been prepared. It seems that although signatures for the direct penetration of the electric fields can indeed be 
observed, some complexities do exist in the sense that there is no one-to-one correspondence between the high-latitude electric fields or currents and the lowlatitude electric fields. The complexities appear to relate not only to changes in the ionospheric electrodynamics but also to changes in the solar wind and the IMF.

Electric-field-penetration events obtained during active periods of the SUNDIAL period (ABDU et al., 1987) have been identified and compared with what the Rice convection model predicts. This study has been conducted by SPIRO et al. (1987). It was found that the degree of the penetration depends fairly sensitively on how hot or cold plasma sheet particles are. For a constant plasma pressure, a cool plasma sheet can shield the electric field more effectively than a hot plasma sheet. It was also suggested that the observed 1-2 hour duration of the electric field effects at low latitudes is possibly the neutral wind effect.

\subsection{Voltage source vs. current source}

The generation mechanism of field-aligned currents has also been studied in terms of the relative importance of a voltage source and a current source. In addition to some of the theoretical considerations, such as those by LYSAK (1985) and KAN and SUN (1985), two interesting data-analysis papers have been published. Those empirical papers focus on trying to find out how the magnetosphere-ionosphere system behaves in response to changing ionospheric conductivity. The method itself seems to be quite simple, but it is in fact not. Because all we can learn about field-aligned currents from data of one polar-orbiting satellite is the current density at that location, we do not gain insight into the grand picture of the field-aligned current intensity. Therefore, we must go through a statistical test using a large number of samples. First, VICKREY et al. (1986) used HILAT observations of electric fields and currents to show that small-scale field-aligned currents must be driven by a constant current generator in the magnetosphere that is independent of the ionospheric conductivity. On the other hand, FUJII and IIJIMA (1987) relied on well-defined region 1 and region 2 currents, which are the large-scale field-aligned currents, from MAGSAT magnetometer data. One of the important findings is that the region 1 and 2 current systems exhibit different dependences on ionospheric conductivities: the region 1 current intensity is nearly proportional to the conductivity at all magnetic local times, but the region 2 current is not. Their conclusion then is that the region 1 system is driven by a voltage generator, whereas region 2 seems to be driven by a combination of voltage and current generators.

LYSAK (1985) studied the structure of currents by coupling Maxwell's equations with Ohm's laws for ionospheric and field-aligned currents as well as currents in the generator region in the magnetosphere. He introduced an effective generator conductivity $\Sigma_{G}$ which allows consideration of a variety of states from a pure current generator (where $\Sigma_{G}=0$ ) to a pure voltage generator (where $\Sigma_{G}=\infty$ ). When time scales of phenomena under study are short and Alfvén waves are important, this effective conductivity mapped down to the polar ionosphere is lower than the ionospheric conductivity, implying a current generator. This is in contrast to many of the earlier theoretical studies of auroral arcs in which generator conditions are assumed fixed. 
One of the main conclusions after computer simulations was that the scale size in $\boldsymbol{X}$ (radial in the magnetosphere or north-south in the ionosphere) is smaller for current generators, indicating that the narrow discrete arcs may be current driven, while the large-scale auroral currents are voltage driven. This is indeed a very promising possibility.

\subsection{Conductivity model}

Models of the ionospheric conductivity have been improved by MISHIN et al. (1986), Robinson et al. (1987), and FULLER-Rowell and Evans (1987), in particular for auroral enhancement conductances. Needless to say, these conductivity models are extremely important in almost all phases of magnetosphere-ionosphere coupling studies, like considering global modeling of magnetospheric convection: see Figs. 1 and 9.

The future direction is to estimate or derive "instantaneous" pictures of ionospheric conductivities for the entire polar region. The studies along this line are being conducted by using DE 1 auroral images (KAMIDE et al., 1986), X-ray images from DMSP (GORNEY et al., 1985), and Viking UV-imager data (MARKLUND et al., 1987).

\subsection{Summary}

Our understanding of the physical processes in the magnetosphere-ionosphere coupling system during the 1985-1987 period has increased in the following respects:

1. Global simulation models are reaching a high level of sophistication through the inclusion of several crucial parameters in magnetosphere-ionosphere coupling in a self-consistent manner, making it possible to start to reproduce many features of observations on an individual basis.

2. Empirical models of high-latitude convection or electrostatic potential for different IMF orientations have been upgraded. The region of particle precipitation relative to the electric field pattern has been determined statistically.

3. Dynamical models of the westward traveling surge, which try to combine pulsation phenomena, have been proposed.

4. Efforts have been made to explain the state of the magnetosphereionosphere system for northward IMF, such as the theta aurora, the four-cell convection pattern, the NBZ current, and neutral winds, in the framework of the large-scale structure of the solar wind magnetosphere-ionosphere system.

5. The efficiency of the electric field penetration into low latitudes has been examined both experimentally and theoretically. The importance of neutral winds in determining the time scale of the electric field response to sudden changes in the IMF is noted.

6. The generation mechanism of field-aligned currents has been studied in terms of the voltage and current generators.

7. Improved "inversion" techniques attempt to combine the growing use of multiple radar observations to sense ionospheric parameters that are coupled with the magnetosphere. Several international joint projects on the basis of new data sets are in 
progress.

Other hot topics include (i) acceleration of auroral electrons and ionospheric ions, and (ii) the evaluation of the sources of high-latitude electric fields. WEIMER et al. (1987) have recently examined high-resolution $\boldsymbol{B}$ and $\boldsymbol{E}$ field data from DE to see if a simple linear Ohm's law relationship exists between the field-aligned current and the parallel potential drop. The answer is Yes, although this relates to the "chicken and egg" problem of the field-aligned currents and potential.

Regarding the sources of electric fields at high latitudes, there are essentially three processes: dayside merging, viscous-like interaction, and ionospheric neutral winds. Data from the Sondrestrom radar and the GEOS satellite, as well as some theoretical considerations of the so-called flywheel or fossil effect of the neutral wind, have contributed significantly to such studies.

\section{The Use of Multiple Sources of Data}

To solve the extremely complex problems of global magnetosphere-ionosphere coupling, it is essential that information from the various data sources and models be examined together in a coherent way. Progress in understanding this complex global system requires combining observations made at different points and using different types of instruments: measurements made at a single point with a single instrument are no longer likely to make an important contribution to understanding the global system. Furthermore, observational results need to be discussed on the basis of existing theoretical models.

In recent years, more and more scientists in this field have combined multiple data sets from a network of separate ground-based observatories and spacecraft to reach a consistent view. In this area of magnetosphere-ionosphere interactions, several joint projects, such as GISMOS and GTMS, have been active. One of the advantages of these joint projects is that not only experimenters and data analysts but theorists and modelers bringing their computer simulation codes join the group to attempt to understand the complex phenomena. In fact, until several years ago, many studies in our field were measuring one parameter (within the entire coupling loop of Fig. 1), assuming a second parameter, and were calculating the third parameter. For example, the electric field was measured, the ionospheric conductivity was assumed, and the ionospheric current was calculated. Such an approach does not necessarily treat the interactive nature of the electric field and the current through conductivities, particle precipitation, and auroral luminosities, and thus the conclusions from such studies are not unique. If we are repeating this kind of work, we cannot properly address the real question of the multifaceted, nonlinear coupling of the magnetosphere-ionosphere system, always addressing "zero-order" or "average" distribution of the parameters.

By the same token, recently developed magnetogram-inversion techniques are powerful tools for sensing the state of convection, currents, and Joule heating on a global scale. However, if we again continue to rely on average data and average conductivity models, we cannot obtain more than the well-known twin-vortex pattern 
in the electrostatic potential. In trying to understand substorms, we must employ highly localized conductivity distributions relating to various forms of auroral enhancements. The last two years have seen some efforts at understanding "more than average" by combining simultaneous measurements of the large number of parameters necessary for studies of magnetosphere-ionosphere coupling. The following are two such examples:

1. RICHMOND and KAMIDE (1987) have proposed a new technique for mapping electrodynamic features, such as the high-latitude electric fields, currents and their associated magnetic fields. It is to generalize earlier magnetogram-inversion schemes in a way that the new technique can use not only ground magnetometer data but also take many different types of measurements of electric fields and conductivities by means of radars and satellites. There is no space to give the mathematical details of the new method in this review, but it should be mentioned that this kind of technique is extremely useful in combining various data sets on the earth's surface and in space, as well as in discussing the magnetosphere-ionosphere coupled system.

Figure 7(a) summarizes the approach of RICHMOND and KAMIDE (1987). The main point of the algorithm is to try to determine consistent patterns of the electrostatic potential, the electric field, the ionospheric current, the field-aligned current, and magnetic perturbations, all of which fit well to the available observations and any a priori information, e.g., statistical properties, we have. Each of these quantities is to be expanded in a series of basis functions in magnetic latitude and local time with the aid of coefficients $\boldsymbol{a}_{\mathrm{i}}$. Figure 7 (b) compares calculated parameters based on an earlier method and the new method for the equivalent current system and the electric potential. Although the two techniques give generally similar results in terms of their large-scale patterns, there are noticeable differences, especially for the electric potentials in the region of low ionospheric conductivities. The new method tends to yield less complex electric fields in the polar cap. Note that the epoch shown in Fig. 7(b) was the maximum phase of an intense substorm.

2. MARKLUND et al. (1987) have calculated global electric field distributions using as input Viking UV data and field-aligned current observed along a satellite orbit. The UV imagery is utilized to locate auroral enhancements in the ionospheric conductance. The calculated electric field is then compared with the electric field observed by the same satellite to adjust the input information. These comparisons and adjustments continue until an optimal agreement is reached between calculated and actually observed electric fields. Figure 8 shows an example of their input, e.g., the model field-aligned current and conductivity distributions, and their output, which is the calculated electrostatic potential.

\section{The Importance of Time-Dependent Treatment}

Coming back to the first question in Section 2 regarding whether we can predict electrodynamic activity or processes in the magnetosphere-ionosphere system only from information on the solar wind, the answer is: Not yet. That is to say, we have not reached the final goal yet. 
IONOSPHERIC ELECTRODYNAMICS MAPPING

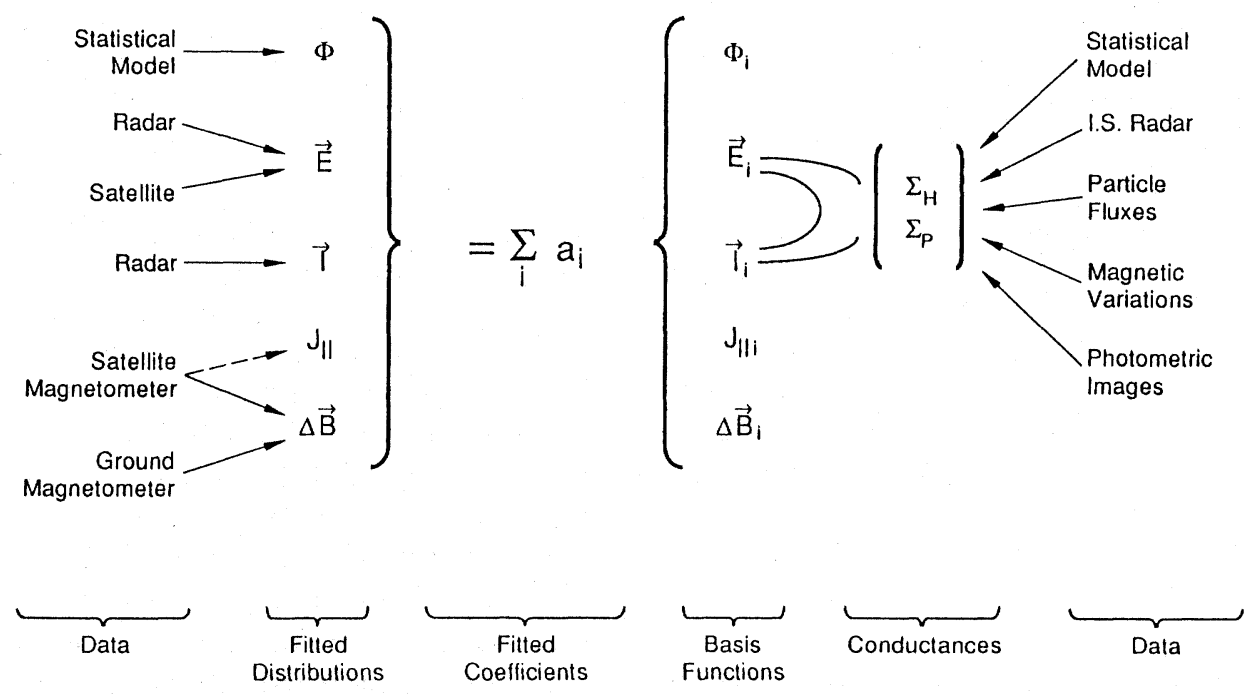

Fig. 7(a). Schematic diagram showing the important elements of the new procedure for mapping electrodynamic features of the high-latitude ionosphere. (After RICHMOND and KAMIDE, 1987).

The next question is then: How far are we now from the final goal? The answer is: It depends on the degree of our satisfaction. Using statistical approaches, for example, even at present we can reproduce more than $50 \%$ of geomagnetic activity using solar wind parameters (CLAUER et al., 1983). Yes, more than 50\%, but we have never reached $100 \%$ or even $70 \%$. In fact, it is important to realize that this number has not improved over the last few years. As long as we are using only geomagnetic indices, without knowing the physics involved in the solar wind-magnetosphereionosphere coupling, there is no hope that we can predict $100 \%$ of what will be happening in the magnetosphere-ionosphere system. Geomagnetic indices are indices. The advantages of having indices are their simplicity, their ready availability, their easy construction, and their rapid circulation in the community.

Until the 1970 s, many people were using the $A E$ index as a substorm or magnetospheric disturbance index. During the last decade, however, people have started to use $A U$ and $A L$, separately, since these two seem to represent two different phenomena and a simple linear sum of apples and oranges (i.e., $A E=A U+|A L|$ ) leads us to an ambiguous physical meaning in $A E$.

How could we improve our understanding of high-latitude electrodynamic processes? Until several years ago, people thought that the magnetosphere and its coupled system with the ionosphere becomes quiet once in a while, when the auroral oval contracts to its minimum size. However, what is "quiet"? In terms of what? We 


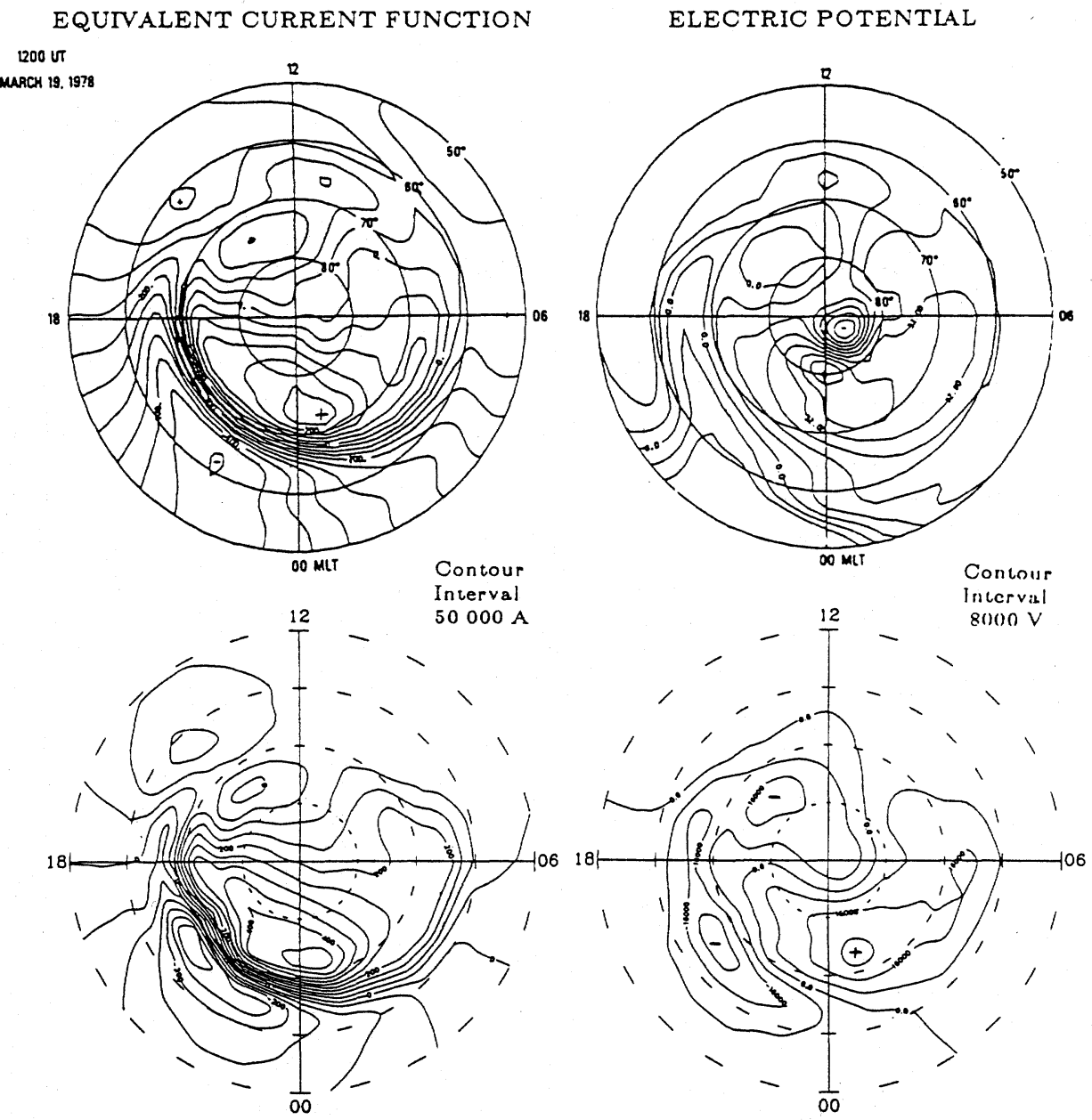

Fig. 7(b). Comparison of the equivalent current function and the electric potential between the mapping procedure of the KRM algorithm (upper diagrams) and that of Richmond and Kamide (lower diagrams).

soon noticed that we did not understand properly the physical meaning of "quiet."We now know that even when the $A E$ index is very small, the highest latitude region is quite active during periods of northward IMF. We now realize that we defined quietness as that time when disturbances were not visible to our eyes located at the standard auroral zone.

Similarly, we may, at present, be tacitly assuming that disturbed times are equivalent to substorm times, but there is no good reason to believe that it is actually 

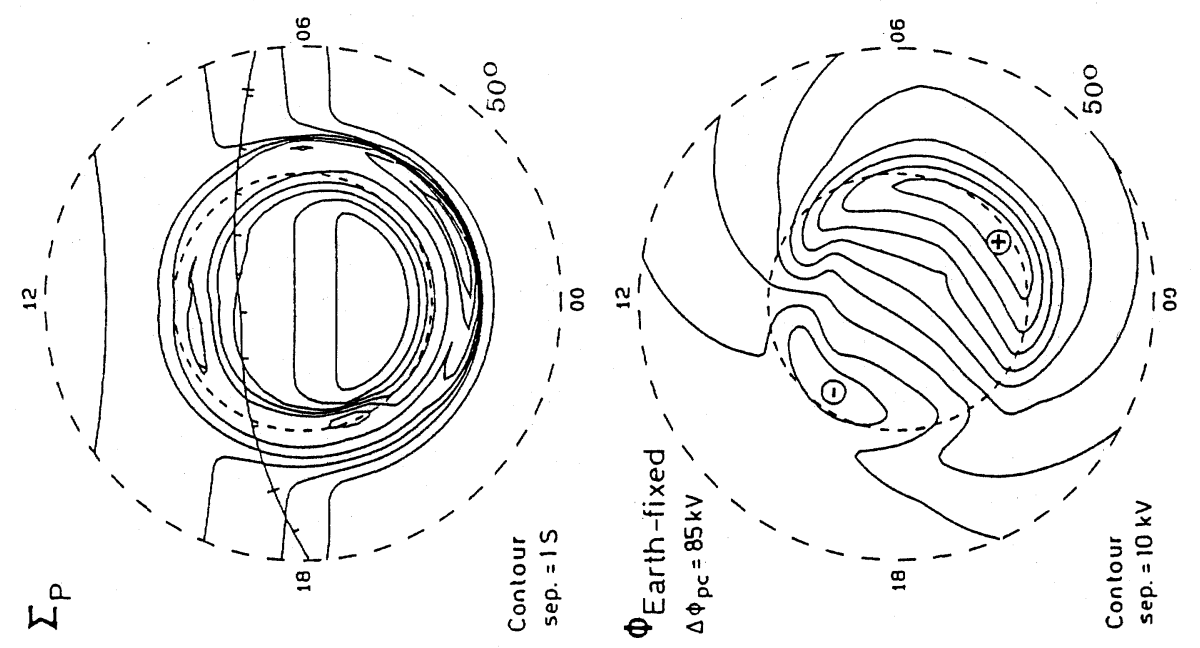

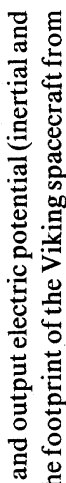

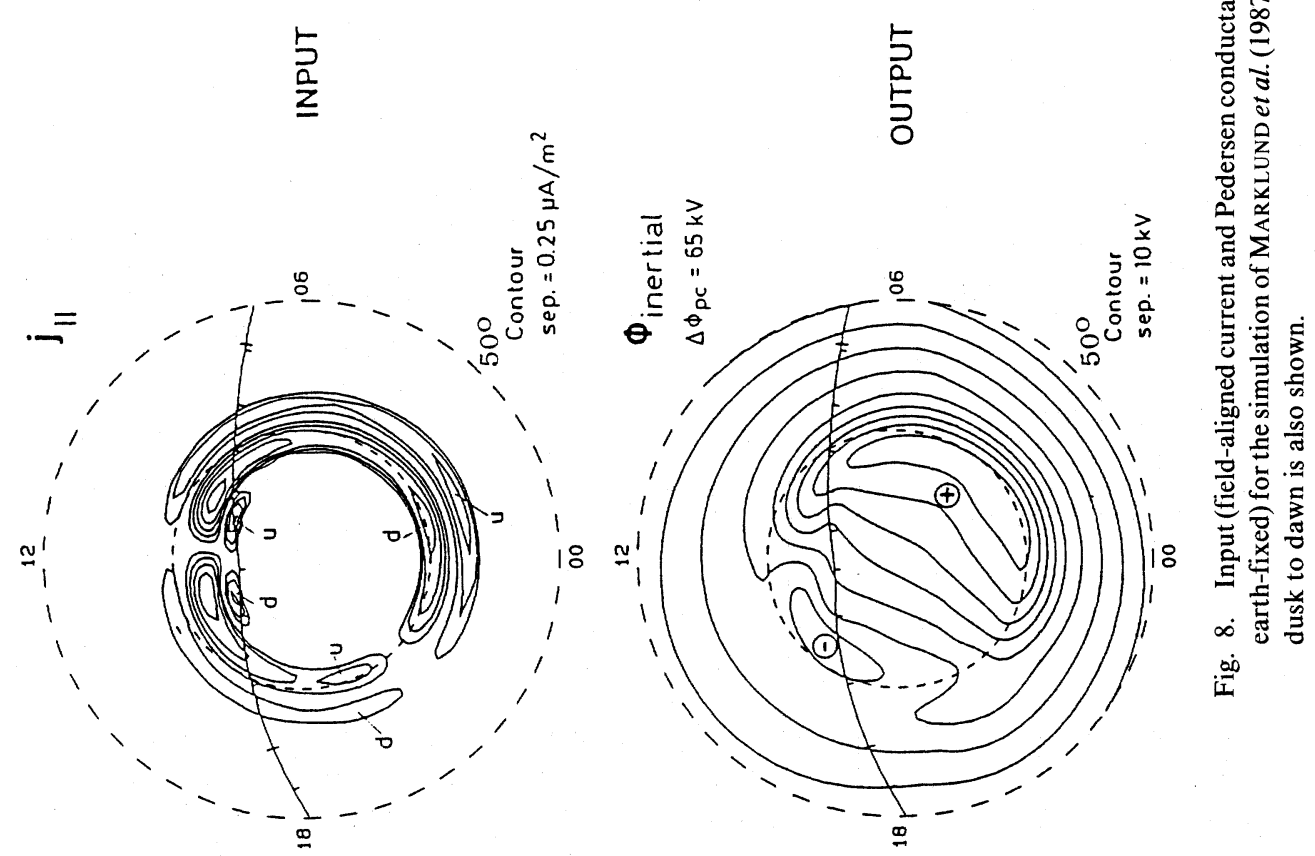


the case. It is one of the urgent problems to distinguish the state of enhanced convection from that of the substorm expansion. These two must be very different in terms of magnetosphere-ionosphere interactions. To distinguish these two processes, one needs to solve the entire coupling system time-dependently.

Figure 9 summarizes some of the most important quantities in the magnetosphereionosphere system to show, in a simple but elegant way, the complicated nature of the interaction of electric fields, plasmas, and currents in the magnetosphere and the ionosphere via geomagnetic field lines. A similar diagram has recently been proposed by M. Blanc (personal communication, 1987). This block diagram consists of nine major boxes. The top three are essentially the magnetospheric quantities and the bottom three are the ionospheric quantities. The three boxes in between are for the space connecting the two regions, or for two plasmas (hot plasma in the magnetosphere and cold ionospheric plasma), although this intermediate region at times cannot be clearly defined. This diagram is arranged in a systematic way to illustrate that, for example in the ionosphere, the electric field and the conductivity control the electric current via Ohm's law, and the electric field in the equatorial plane of the magnetosphere is mapped down to the ionosphere through geomagnetic field lines, subject to modifications by the so-called parallel electric fields.

It is important, however, to argue that the ionosphere is not only a passive medium. The ionospheric electric field is to be changed by polarization charges
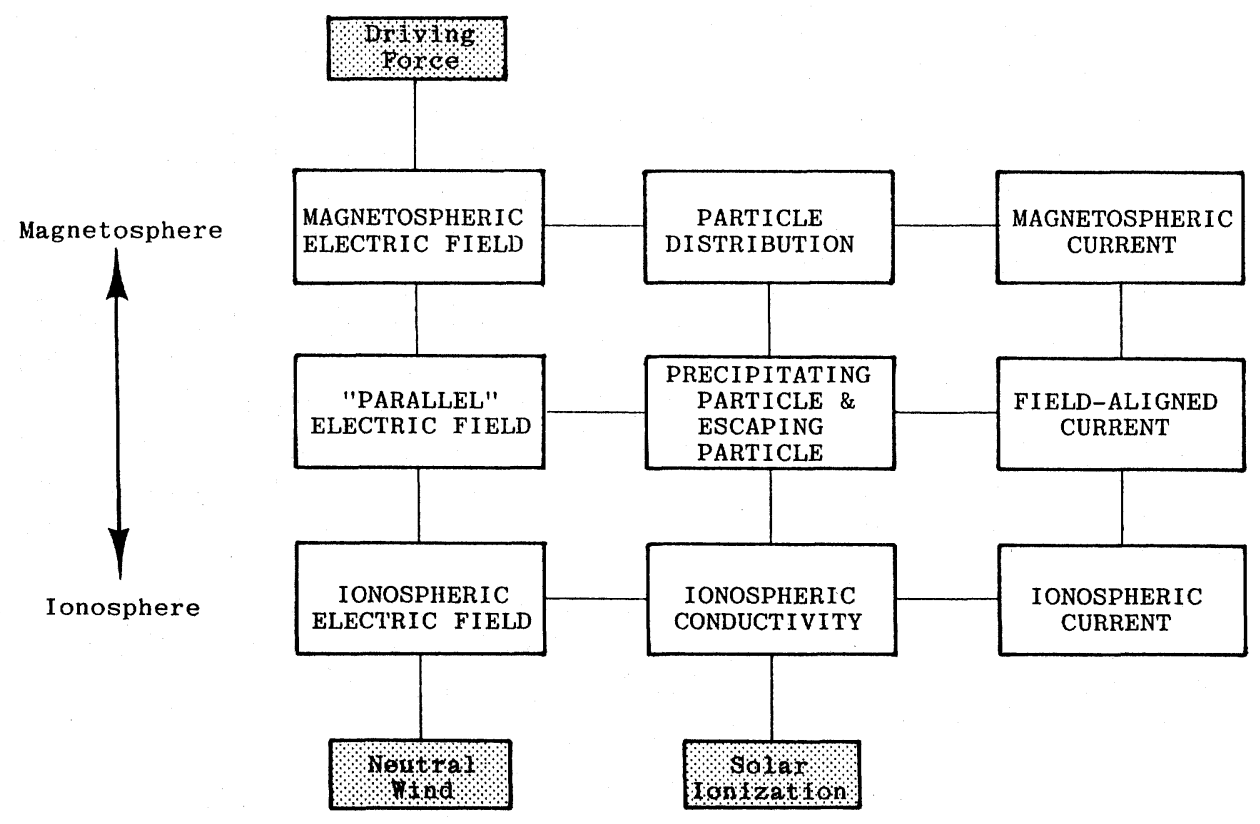

Fig. 9. Block diagram showing electrodynamic coupling between the magnetosphere and the ionosphere. 
deposited by ionospheric currents near strong gradients in the conductivity distribution. The main point of interest in Fig. 9 is to emphasize that although most of the recent simulation studies treat only the outermost links of the boxes, it is essential to realize that all nine boxes are mutually connected. For example, the rate of particle precipitation onto the polar ionosphere is regulated by the particle distribution in the magnetosphere, which is influenced by both the main charge carriers of field-aligned currents, which are of course regulated by the existence of the parallel electric field (WEIMER et al., 1985).

Another inevitable complication in understanding this diagram lies in the fact that the entire system is not totally time-independent, although block diagrams of this type neglect the dynamics of the coupling processes in the magnetosphere-ionosphere system. That is, temporal changes in these quantities that occur in the real-life magnetosphere-ionosphere system are not merely the results of repetitions of quasisteady states separated by $\Delta t$. For instance, auroral enhancements in the ionospheric conductivity are not in fact directly related to and are not instantly determined by precipitating energetic electrons. As is well known, the electron density that determines the conductance is the outcome of the balance of the ionization production and recombination rates which have certain characteristic time constants, like several minutes. Thus, without knowing the details of the physical interaction between ionized and neutral particles, it is not possible to treat that link selfconsistently and time dependently. For similar reasons, dynamical changes in the parallel electric field in charge of accelerating auroral electrons are crucial to the unfolding of the expansive onset of substorms, which no presently available computer simulation study can explain properly. This relates to the problem of "convection" type and "substorm expansion" type disturbances.

All in all, we are just beginning to understand only the average state of the magnetosphere-ionosphere system in which in fact many time-dependent and nonlinear processes are taking place. At present, we do not even know how sudden is "sudden," although the substorm expansion is often described in terms of a "sudden" increase in observed parameters, such as the auroral brightness and the electrojet intensity, as well as a "sudden" change in the direction of the electric field in the midnight sector. Last, but not least, it is important to note that the substorm time scales depend also on how substorm energy is stored in the magnetotail and how it is released toward the polar ionosphere and the inner magnetosphere. Progress in studies of magnetospheric substorms in the magnetotail is evaluated in a companion paper (BAUMJOHANN, 1988).

I would like to thank G. Atkinson, W. Baumjohann, M. Blanc, C. O. Hines, and A. Nishida for their useful comments. This work was supported in part by the Ministry of Education in Japan through grant 62540310 , and in part by the National Institute of Polar Research through a joint research program. 


\section{REFERENCES}

Abdu, M. A., B. M. Reddy, G. O. Walker, R. Hanbab, J. H. Sobral, B. G. Fejer, R. F. Woodman, R. W. Schunk, and E. Szuszozewicz, The quiet and disturbed equatorial-low latitude ionospheric processes, from analyses of the global Sundial data set, Ann. Geophys., 5A, 1987 (in press).

Ahn, B.-H., Y. Kamide, S.-I. AKasofu, and C.-I. Meng, Convection Patterns in the polar ionosphere for northward IMF inferred from ground-based magnetometer data, J. Geomag. Geoelectr., 39, 313-331, 1987.

Alcayde, D., G. Caudal, and J. Fontanari, Convection electric fields and electrostatic potential over $61^{\circ}<\Lambda<72^{\circ}$ invariant latitude observed with the European incoherent scatter facility, 1. Initial results, J. Geophys. Res., 91, 233-247, 1986.

AtKinson, G., The role of currents in plasma redistribution, in Magnetospheric Currents, edited by T. A. Potemra, pp. 325-330, Amer. Geophys. Union, Washington, D. C., 1984.

Baumjohann, W., The plasma sheet boundary layer and magnetospheric substorms, J. Geomag. Geoelectr., 40, this issue, 1988.

Clauer, C. R., R. L. MCPherron, and C. Searls, Solar wind control of the low-latitude asymmetric magnetic disturbance field, J. Geophys. Res., 88, 2123-2130, 1983.

Cornwall, J. M., Idealized model of polar cap currents, fields, and aurora, J. Geophys. Res., 90, 3541-3544, 1985.

FÄlthammaR, C.-G., Magnetosphere-ionosphere interactions-Near earth manifestations of the plasma universe, IEEE Trans. on Plasma Sci., P5-14, 616-628, 1986.

FEJER, B. G., Equatorial ionospheric electric fields associated with magnetospheric disturbances, in Solar Wind-Magnetosphere Coupling, edited by Y. Kamide and J. A. Slavin, pp. 519-545, Terra/Reidel, Tokyo, 1986.

Fontaine, D., M. Blanc, L. Reinhart, and R. Glowinski, Numerical simulations of the magnetospheric convection including the effects of electron precipitation, J. Geophys. Res., 90, 8343-8360, 1985.

Foster, J. C., Reply to Kamide and Richmond, Geophys. Res. Lett., 14, 160-161, 1987.

Foster, J. C., J. M. Holt, R. G. Musgrove, and D. S. Evans, Ionospheric convection associated with discrete levels of particle precipitation, Geophys. Res. Lett., 13, 656-659, 1986.

Frank, L. A., J. D. Craven, D. A. Gurnett, S. D. Shawnhan, D. R. Weiner, J. L. Burch, J. D. Winningham, C. R. Chappell, J. H. Waite, R. A. Heelis, N. C. Maynard, M. Sugiura, W. K. Peterson, and E. G. Shelley, The theta aurora, J. Geophys. Res., 91, 3177-3224, 1986.

FujII, R. and T. IIJIMA, Control of the ionospheric conductivities on large-scale Birkeland current intensities under geomagnetic quiet conditions, J. Geophys. Res., 92, 4505-4513, 1987.

Fuller-Rowell, T. J. and D. S. Evans, Height integrated Pedersen and Hall conductivity patterns inferred from the TIROS-NOAA satellite data, J. Geophys. Res., 92, 7606-7618, 1987.

GORNEY, D. J., U.S. progress in auroral research: 1983-1986, Rev. Geophys., 25, 555-569, 1987.

Gorney, D. J., P. F. Mizera, and J. L. Roder, A maximum-entropy technique for deconvolution of atmospheric bremsstrahlung spectra, Space Sci. Lab. Rep. No. SSL-86 (6940-06)-06, 23 pp., 1985.

Hardy, D. A., M. S. Gussenhoven, and E. Holeman, A statistical model of auroral electron precipitation, J. Geophys. Res., 90, 4229-4248, 1985.

HeElis, R. A., Electrodynamics and plasma processes in the ionosphere, Rev. Geophys., 25, 419-432, 1987.

HePPNer, J. P., Empirical models of high latitude electric fields, J. Geophys. Res., 82, 1115-1125, 1977.

Heppner, J. P. and N. C. Maynard, Empirical high-latitude electric field models, J. Geophys. Res., 92, 4467-4490, 1987.

Holt, J. M., R. H. WAND, J. V. Evans, and W. L. Oliver, Empirical models for the plasma convection at high latitudes from Millstone Hill observations, J. Geophys. Res., 92, 203-212, 1987.

Kamide, Y. and A. D. Richmond, Recent advances in studies of magnetosphere-ionosphere coupling, $J$. Geomag. Geoelectr., 38, 653-714, 1986.

KAMIDE, Y. and A. D. RICHMOND, Comment on "Ionospheric convection associated with discrete levels of particle precipitation," Geophys. Res. Lett., 14, 158-159, 1987.

Kamide, Y., J. D. Craven, L. A. Frank, B.-H. Ahn, and S.-I. Akasofu, Modeling substorm current systems using the conductivity distribution inferred from DE auroral images, J. Geophys. Res., 91, 
$11235-11256,1986$.

KAN, J. R. and W. J. Burke, A theoretical model of polar cap auroral arcs, J. Geophys. Res., 90, 4171$4177,1985$.

KAN, J. R. and W. Sun, Simulation of the westward traveling surge and $\mathrm{Pi} 2$ pulsations during substorms, J. Geophys. Res., 90, 10911-10922, 1985.

Killeen, T. L., P. B. Hays, G. R. Carignan, R. A. Heelis, W. B. Hanson, N. W. Spencer, and L. H. BRACE, Ion-neutral coupling in the high-latitude $F$-region: Evaluation of ion heating terms from Dynamic Explorer 2, J. Geophys. Res., 89, 7495-7508, 1984.

Killeen, T., R. A. Heelis, P. B. Hays, N. W. Spencer, and W. B. Hanson, Neutral motions in the polar thermosphere for northward interplanetary magnetic field, Geophys. Res. Lett., 12, 159-162, 1985.

Lyons, L. R., A simple model for polar cap convection patterns and generation of $\theta$ auroras, J. Geophys. Res., 90, 1561-1567, 1985.

Lyons, L. R., T. A. Killeen, and R. L. Walterscheid, The neutral wind "flywheel" as a source of quiet-time, polar-cap currents, Geophys. Res. Lett., 12, 101-104, 1985.

LYSAK, R. L., Auroral electrodynamics with current and voltage generators, J. Geophys. Res., 90, 4178-4190, 1985.

Marklund, G. T., L. G. Blomberg, T. A. Potemra, J. S. Murphree, F. J. Rich, and K. Stasiewicz, A new method to derive "instantaneous" high-latitude potential distributions from satellite measurements including auroral imager data, Geophys. Res. Lett., 14, 439-442, 1987.

MAUK, B. H. and L. J. ZANETTI, Magnetospheric electric fields and currents, Rev. Geophys., 25, 541-554, 1987.

Mazaudier, C., C. Senior, and E. Nielsen, Global convection electric field and current: Comparisons between model's predictions and data from STARE, Saint-Santin, and magnetometers, J. Geophys. Res., 92, 5991-5999, 1987.

Mishin, V. M., S. B. Lunyushinin, D. S. Shirapov, and W. Baumjohann, A new method for generating instantaneous ionospheric conductivity models using ground-based magnetic data, Planet. Space Sci., 34, 713-722, 1986.

RASMuSSEn, C. E. and R. W. Schunk, Ionospheric convection driven by NBZ currents, J. Geophys. Res., 92, 4491-4504, 1987.

Richmond, A. D. and Y. KAmide, Mapping electrodynamic features of the high-latitude ionosphere from localized observations: Technique, J. Geophys. Res., 1987 (in press).

Robinson, R. M., R. R. VondraK, K. Miller, T. DabBs, and D. A. HaRdy, On calculating ionospheric conductances from the flux and energy of precipitating electrons, J. Geophys. Res., 92, 2565-2569, 1987.

Roble, R. G., B. A. Emery, R. E. Dickinson, E. C. Ridley, T. L. Killeen, P. B. Hays, G. R. Carignan, and N. W. SPENCER, Thermospheric circulation, temperature and compositional structure of the southern hemisphere polar cap during October-November, 1981, J. Geophys. Res., 89, 9057-9068, 1984.

Rothwell, P. L., M. B. Silevitch, and L. P. Block, A model for the propagation of the westward traveling surge, J. Geophys. Res., 89, 8941-8948, 1984.

Rothwell, P. L., M. B. Silevitch, and L. P. Block, Pi 2 pulsations and the westward traveling surge, $J$. Geophys. Res., 91, 6921-6928, 1986.

SAto, T., Auroral physics, in Magnetospheric Plasma Physics, edited by A. Nishida, pp. 197-243, Terra/Reidel, Tokyo, 1982.

SENIOR, C. and M. BLANC, On the control of magnetospheric convection by the spatial distribution of ionospheric conductivities, J. Geophys. Res., 89, 261-284, 1984.

SisCOE, G. L., Topics in magnetosphere-ionosphere coupling (abstract), in Quantitative Modeling of Magnetosphere-Ionosphere Coupling Processes, edited by Y. Kamide and R. A. Wolf, pp. 343-348, Kyoto Sangyo University, 1987.

SPIRo, R. W., R. A. Wolf, and B. G. FEJER, Penetration of high-latitude electric field effects to low latitudes during SUNDIAL 1984, Ann. Geophys., 5A, 1987 (in press).

Sun, W. and J. R. KAN, A transient-response theory of Pi 2 pulsations, J. Geophys. Res., 90, 4395-4397, 1985. 
TANAKA, T., Low-latitude ionospheric disturbances: Results for March 22, 1979, and their general characteristics, Geophys. Res. Lett., 13, 1399-1402, 1986.

Vasyliunas, V. M., Mathematical models of magnetospheric convection and its coupling to the ionosphere, in Particles and Fields in the Magnetosphere, edited by B. M. McCormac, pp. 60-71, Reidel, Hingham, MA, 1970.

Vickrey, J. F., R. C. Livingston, N. B. Walker, T. A. Potemra, R. A. Heelis, M. C. Kelley, and F. J. $\mathrm{RICH}$, On the current-voltage relationship of the magnetospheric generator at intermediate spatial scales, Geophys. Res. Lett., 13, 495-498, 1986.

Watanabe, K., M. Ashour-Abdalla, and T. Sato, A numerical model of magnetosphere-ionosphere coupling: Preliminary results, J. Geophys. Res., 91, 6973-6978, 1986.

Weimer, D. R., C. K. Goertz, D. A. Gurnett, N. C. Maynard, and J. L. Burch, Auroral zone electric fields from DE 1 and 2 at magnetic conjunctions, J. Geophys. Res., 90, 7479-7494, 1985.

Weimer, D. R., D. A. Gurnett, C. K. Goertz, J. D. Menietti, J. L. Burch, and M. Sugiura, The current-voltage relationship in auroral current sheet, J. Geophys. Res., 92, 187-194, 1987.

Wolf, R. A., G. A. Mantjoukis, and R. W. Spiro, Theoretical comments on the nature of the plasmapause, Adv. Space Res., 6, 177-186, 1986.

ZI, M.-Y. and C.-S. SHEN, A time-dependent analytical model with day-night ionospheric conductivity gradient for magnetospheric convection, Planet. Space Sci., 34, 353-362, 1986. 